\section{Effect of temperature on creamatocrit method}

Since the description of the creamatocrit method for estimating the fat concentration and energy in human milk ${ }^{1}$ this technique has been used widely for quality control in human milk banks and in various studies. A study was carried out to assess the effect of the temperature to which milk samples are subjected before and during analysis.

\section{Methods and results}

The study was designed to simulate the possible range of conditions under which milk fat content might be estimated in different laboratories. The fat content in each of 24 specimens of fresh human milk was estimated by the creamatocrit technique: $(a)$ with the centrifuge run in a cold room at $4^{\circ} \mathrm{C},(b)$ with the centrifuge run at room temperature $\left(18^{\circ} \mathrm{C}\right)$, and $(c)$ at room temperature with a centrifuge that had been "prewarmed" by being run continuously for 30 minutes before use, as might occur with a centrifuge in regular use. The 24 milk samples were then pasteurised at $62^{\circ} \mathrm{C}$ for 30 minutes and the fat content again measured under the same conditions. In each case creamatocrit values were calculated by the published formula ${ }^{1}$ relating percentage cream $(C)$ to fat content : fat $(\%)=(C-0 \cdot 59)$ / 1.46. A subsample of each of the 24 specimens of fresh milk was also analysed for fat content by the Gerber reference method. ${ }^{2}$ The creamatocrit values in each group were tested for linear correlation with values obtained by the Gerber method and with values determined in each of the other groups. The mean fat contents of the 24 samples in each group were compared with each other by paired $t$ test.

The table shows the mean fat contents of the 24 samples of fresh and pasteurised milk estimated by the creamatocrit and the Gerber reference method. Only samples of fresh milk tested at room temperature had a similar

Mean $(S D)$ milk fat $(\mathrm{g} / 100 \mathrm{ml})$ measured in 26 samples by creamatocrit method under various conditions and by Gerber method

\begin{tabular}{|c|c|c|c|}
\hline Creamatocrit method & $\begin{array}{l}\text { Fresh } \\
\text { milk }\end{array}$ & $\begin{array}{l}\text { Pasteurised } \\
\text { milk }\end{array}$ & $\begin{array}{l}\text { Gerber } \\
\text { method }\end{array}$ \\
\hline $\begin{array}{l}\text { Centrifugation at } 4^{\circ} \mathrm{C} \\
\text { Centrifugation at room temperature } \\
\text { Prerun centrifuge at room temperature }\end{array}$ & $\begin{array}{l}3.32(1.51) \\
(r=0.931)^{*} \\
2.73(1.17) \\
(r=0.963) \\
2.45(1.14) \\
(r=0.981)\end{array}$ & $\begin{array}{l}2.99(1.36) \\
(r=0.969) \\
2 \cdot 21(1.12) \\
(r=0.974) \\
2 \cdot 09(1.12) \\
(r=0.981)\end{array}$ & $\left\{\begin{array}{l}2 \cdot 66(1 \cdot 18) \\
(\text { range } 1 \cdot 0-6 \cdot 2)\end{array}\right.$ \\
\hline
\end{tabular}

* Linear correlation between creamatocrit values and values obtained by Gerber method.

fat content as estimated by the creamatocrit method to that determined by the Gerber method (these conditions approximate to those under which the creamatocrit method was calibrated originally ${ }^{1}$ ); in all other instances the calculated mean fat values were significantly lower or higher than the standard $(p<0.001)$. Furthermore, at each temperature previous pasteurisation of the milk resulted in a significantly lower estimated fat concentration $(p<0.001)$. Under all conditions studied, however, the creamatocrit values showed a high linear correlation with values determined by the Gerber method ( $r=0.931$ to $0.981, \mathrm{p}<0.001$ ).

\section{Comment}

The creamatocrit method is used often in clinical practice and is especially valuable in assessing nutrient intakes of sick and low birthweight infants fed on banked breast milk. Thus it is important that the results are accurate. In this study, however, the temperature to which milk samples are subjected during centrifugation was found to exert a significant effect on the fat values calculated by the creamatocrit method. ${ }^{1}$ The wide variety of temperatures likely to exist in different countries and laboratories together with variation in the usage and condition of the haematocrit centrifuge used (poorly serviced centrifuges are more likely to overheat during use) all result in unacceptably large variations in calculated fat values. Furthermore, many milk banks conduct quality control on pasteurised milk, yet this study showed that calculated fat values. were significantly lower in pasteurised than in fresh milk (this conflicts with previous observations, made without controlling environmental temperature ${ }^{1}$ ). Even at a constant environmental temperature of $18^{\circ} \mathrm{C}$, fresh milk samples had a fat content over $30^{\circ}$, higher than that of pasteurised milk spun in a centrifuge warmed up by repeated use; and when the environmental temperature was altered considerably greater differences were observed.

These results may be partly explained by the effect of heat in disrupting the fat globule membrane, the released fat occupying less space than cream, which is a suspension of fat in the aqueous phase of milk. Nevertheless, the close linear correlation between fat estimations performed by the Gerber creamatocrit method under all the conditions studied shows the validity of the creamatocrit technique. Clearly, however, the method must be standardised for the conditions that exist in any particular laboratory.

I am indebted to Mr Peter Simpson and Mr Brain Baker for their technical help.

1 Lucas A, Gibbs JAH, Lyster RLJ, Baum JD. Creamatocrit : simple clinical technique for estimating fat concentration and energy value of human milk. Br Med F 1978;i:1018-20.

${ }^{2}$ British Standards Institution. Gerber method for determination of fat in milk and milk products (BS696). London: British Standards Institution, 1955.

(Accepted 21 April 1983)

MRC Dunn Nutrition Unit, Cambridge, and Cambridge University Department of Paediatrics

A LUCAS, MRCP, MRC senior scientific staff and honorary lecturer

Correspondence to: Dr A Lucas, Dunn Nutritional Laboratory, Milton Road, Cambridge CB4 1XJ.

\section{Massive digoxin overdose: successful treatment with intravenous amiodarone}

Massive digoxin overdosage is difficult to treat and has a mortality of $10-20 \%$. Atropine may be useful in mild overdosage but is of little value in severely poisoned patients. Phenytoin is effective in moderately poisoned patients, but in severe cases conventional antiarrhythmics including lignocaine, phenytoin, practolol, procainamide, and verapamil seem to be ineffective. ${ }^{1}$ Antigen binding fragments of digoxin specific antibodies, though effective, ${ }^{2}$ are not widely available. Even cardiac pacing may be unsuccessful in severely poisoned patients. We report on a patient with intractable ventricular fibrillation after digoxin overdosage who was successfully treated with intravenous amiodarone over 24 hours.

\section{Case report}

A previously well 26 year old man was admitted to hospital 18 hours after ingesting $1000.25 \mathrm{mg}$ digoxin tablets. On admission he was conscious but complained of unsteadiness and blurred vision. Examination showed a sinus bradycardia of 50 beats $/ \mathrm{min}$, and an electrocardiogram showed considerable ST depression and second degree heart block (PR interval $0.36 \mathrm{~s}$ ). Blood pressure was satisfactory at $115 / 70 \mathrm{~mm} \mathrm{Hg}$, and there were no other abnormalities. Electrolyte concentrations were normal apart from the serum potassium concentrations, which subsequently rose from $5 \cdot 1 \mathrm{mmol}(\mathrm{mEq}) / 1$ to $6.2 \mathrm{mmol} / 1$.

Activated charcoal was administered in the casualty department after gastric lavage. One hour after admission to the coronary care unit he developed ventricular tachycardia with rapid progression to ventricular fibrillation. He was intubated and ventilated with $100 \%$ oxygen and in addition received intravenous sodium "bicarbonate $8.4 \%$ and external cardiac massage. Several attempts at cardioversion, increasing from $100 \mathrm{~J}$ to $400 \mathrm{~J}$, failed to induce defibrillation: After intravenous lignocaine (up to $200 \mathrm{mg}$ ) a further attempt at cardioversion resulted in asystole, which responded satisfactorily only to intracardiac adrenaline. Pacing facilities were not available, and he was too ill to be moved.

The sequence of events was repeated with further episodes of prolonged ventricular fibrillation unresponsive to defibrillation. After 30 minutes of resuscitation amiodarone $300 \mathrm{mg}$ was administered intravenously over 20 minutes while external cardiac massage and ventilation were continued. One hour after the start of resuscitation he was successfully defibrillated 